Article

\title{
Experimental and Computational Study of the Properties of Imidazole Compounds with Branched and Cycloalkyl Substituents
}

\author{
Shuai Qian (D), Patrick Mileski (D), Adam C. Irvin, Ademola Soyemi, Tibor Szilvási and Jason E. Bara *(D)
}

Citation: Qian, S.; Mileski, P.; Irvin, A.C.; Soyemi, A.; Szilvási, T.; Bara, J.E. Experimental and Computational Study of the Properties of Imidazole Compounds with Branched and Cycloalkyl Substituents. Liquids 2022, 2, 14-25. https://doi.org/10.3390/ liquids2010002

Academic Editor: Enrico Bodo

Received: 18 October 2021

Accepted: 31 January 2022

Published: 7 February 2022

Publisher's Note: MDPI stays neutral with regard to jurisdictional claims in published maps and institutional affiliations.

Copyright: (C) 2022 by the authors. Licensee MDPI, Basel, Switzerland. This article is an open access article distributed under the terms and conditions of the Creative Commons Attribution (CC BY) license (https:// creativecommons.org/licenses/by/ $4.0 /)$.
Department of Chemical and Biological Engineering, University of Alabama, Tuscaloosa, AL 35487-0203, USA; sqian4@crimson.ua.edu (S.Q.); pmileski99@gmail.com (P.M.); acirvin@crimson.ua.edu (A.C.I.); asoyemi@crimson.ua.edu (A.S.); tibor.szilvasi@ua.edu (T.S.)

* Correspondence: jbara@eng.ua.edu

\begin{abstract}
N$-functionalized imidazole compounds with linear alkyl groups have been widely utilized precursors for imidazolium ionic liquids (ILs) while the effects of branched and cycloalkyl substituents on properties of imidazole compounds have not been studied; however, such compounds are just as synthetically accessible as those with linear alkyl groups. In this work, two fundamental properties, density and viscosity, of selected $N$-functionalized imidazoles bearing iso-propyl, iso-butyl, sec-butyl methylcyclopropyl, cyclopentyl, and methylcyclohexyl groups have been measured in the temperature range of 293.15-353.15 K for the guidance of molecular design for future applications. A linear and parabolic model were used for temperature-density correlation while temperature dependence of viscosity was summarized using the Andrade Equation and the Vogel-Fulcher-Tammann equation. In addition to experimental data, density, viscosity, vapor pressure and vaporization of enthalpies of target imidazole compounds were predicted using COSMOtherm calculations and compared with experimental data. It was found that the calculated densities were quite close to the experimental data, while viscosity data, obtained from COSMOtherm, underestimated experimental measurements and a scaling factor provided agreement with experiments. Predictions of vapor pressure were relatively reliable at low temperature, although the difference between experiment and prediction tended to expand with increasing temperature. Variances of vaporization enthalpies were small upon temperature change and a maximum error of $\sim 12.3 \%$ was observed for all compounds studied.
\end{abstract}

Keywords: imidazole; functional groups; density; viscosity; COSMOtherm calculation

\section{Introduction}

Ionic liquids (ILs), a well-known class of molten salts, have attracted great research interest and have been the subject of much study during the last 20+ years owing to their unique combinations of properties. Among the cations that can be used for IL design, the 1-n-alkyl-3-methylimidazolium $\left(\left[\mathrm{C}_{\mathrm{n}} \mathrm{mim}\right]\right)$ motif is a common choice and the properties of these ILs relating to the length of the n-alkyl substituent have been thoroughly measured and modeled. Imidazolium ILs have been used as substitutes for conventional organic solvents and have been successfully used in applications including polymer solvation [1], gas separation [2-4], metal extraction [5,6], biomaterial preparation [7-9] and energy storage including fuel cells [10,11], Li+-ion batteries [11,12] and supercapacitors [13].

While imidazolium ILs are tunable through modification of the cation and/or anion moieties, the customizability of the imidazolium cation provides many more possibilities, compared to a relatively limited reservoir of candidate anions. Imidazole is an excellent building block which allows convenient grafting of functional groups to the $\mathrm{N}$ atoms of the five-membered ring [14], allowing for great versatility in the design of N-functionalized imidazoles and corresponding imidazolium ILs. Moreover, $N$-functionalized imidazoles 
have a plethora of other uses such as metal extraction [15,16], gas separation [17], temperature swing solvent extraction (TSSE) [18] and can provide correlations for prediction on densities of corresponding ILs [19].

In the family of $\mathrm{N}$-functionalized imidazoles, most research efforts have focused on understanding the properties of $\mathrm{N}$-alkylimidazole compounds with linear/straight chains including density [20,21], viscosity [22], vapor pressure [23-26], heat capacity [27], and $\mathrm{p} K_{\mathrm{a}}$ [28]. However, the properties of $\mathrm{N}$-alkylimidazoles with branched or cycloalkyl functional groups have been rarely studied, although the synthesis of such compounds is no more difficult or expensive than the linear alkyl counterparts. The study of $\mathrm{N}$ alkylimidazoles with branched or cycloalkyl groups will further understanding of imidazoles and corresponding ILs.

In this work, three branched and three cycloalkyl imidazole compounds were studied as shown in Table 1. Two fundamental properties, density and viscosity, were measured in temperature range of $293.15-353.15 \mathrm{~K}$ and equations for correlation between temperature and corresponding properties were derived from experimental data for extrapolation and guidance for molecular design of neutral alkylimidazole analogues. In addition to experimental data, COSMOtherm calculations were conducted and data from different sources were compared.

Table 1. Names, formulas, and structures of imidazole compounds studied in this work.

\begin{tabular}{|c|c|c|c|}
\hline Compound \# & Name/CAS \# & Formula & Structure \\
\hline 1 & $\begin{array}{c}\mathrm{N} \text {-isopropylimidazole } \\
4532-96-1\end{array}$ & $\mathrm{C}_{6} \mathrm{H}_{10} \mathrm{~N}_{2}$ & \\
\hline 2 & $\begin{array}{c}\text { N-isobutylimidazole } \\
16245-89-9\end{array}$ & $\mathrm{C}_{7} \mathrm{H}_{12} \mathrm{~N}_{2}$ & \\
\hline 3 & $\begin{array}{l}\text { N-sec-butylimidazole } \\
\text { 20075-29-0 }\end{array}$ & $\mathrm{C}_{7} \mathrm{H}_{12} \mathrm{~N}_{2}$ & \\
\hline 4 & $\begin{array}{l}\text { N-cyclopropylmethylimidazole } \\
717908-74-2\end{array}$ & $\mathrm{C}_{7} \mathrm{H}_{10} \mathrm{~N}_{2}$ & \\
\hline 5 & $\begin{array}{c}\text { N-cyclopentylimidazole } \\
71614-58-9\end{array}$ & $\mathrm{C}_{8} \mathrm{H}_{12} \mathrm{~N}_{2}$ & \\
\hline 6 & $\begin{array}{l}\text { N-cyclohexylmethylimidazole } \\
\text { 71621-00-6 }\end{array}$ & $\mathrm{C}_{10} \mathrm{H}_{16} \mathrm{~N}_{2}$ & \\
\hline
\end{tabular}

\section{Materials and Methods}

\subsection{Materials}

All the $N$-functionalized imidazole compounds studied in this work were synthesized as shown in Scheme 1, in which imidazole was deprotonated by $\mathrm{NaOH}$, creating sodium imidazolate as an intermediate towards the formation of modified imidazoles via reaction with corresponding halide compounds. Detailed synthetic procedures for these compounds can be found in our prior works $[29,30]$. Compounds $\mathbf{1 - 6}$ used for characterizations were determined to contain $<5 \times 10^{-4}$ mass fraction of impurities by Hewlett-Packard 5890 Series II gas chromatography with a flame ionization detector. ${ }^{1} \mathrm{H}$ NMR data obtained from a Bruker AVANCE $500 \mathrm{MHz}$ NMR spectrometer in the Chemistry Department at the University of Alabama showed good consistency with previously published spectra and can be found in our previous publication [30] as they were from the same batch of 
reactions. All compounds were further purified by distillation under reduced pressure prior to density and viscosity measurements.

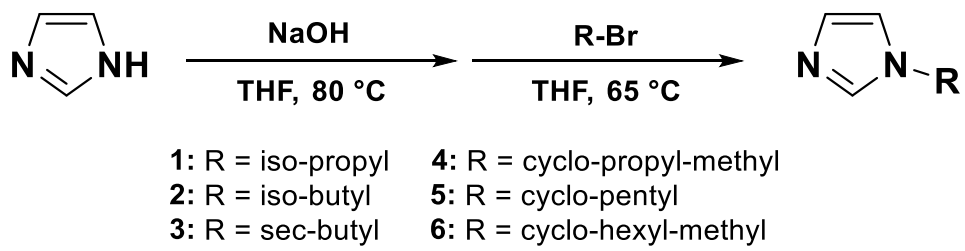

Scheme 1. Synthesis of $N$-functionalized imidazoles using imidazolate method.

\subsection{Density Measurements}

Densities of imidazole compounds were measured using a Mettler Toledo DM45 DeltaRange density meter through oscillation of a U-tube induced by electromagnetic effect. The measurements were conducted under atmosphere pressure with variations compensated automatically. The glass U-tube was rinsed with acetone before and after each run, followed by air flow to guarantee the dryness of the tube. A minimum volume of $1.2 \mathrm{~mL}$ was required for the injection of samples to fill the U-tube. Samples were loaded at ambient temperature $(\sim 293 \mathrm{~K})$ and the density meter started to collect data starting at $293.15 \mathrm{~K}$, and more data were collected at different temperatures with an increment of $10 \mathrm{~K}$ controlled by the preset program until it reached $353.15 \mathrm{~K}$. As a result, seven data points were collected for each compound.

\subsection{Viscosity Measurements}

Viscosities of imidazole compounds were measured using a Brookfield DV-II + Pro viscometer. Viscosity was calculated automatically based on corresponding torque value and shear rate of the "ULA" spindle. For each measurement, around $20 \mathrm{~mL}$ liquid was used to fill the sample chamber such that the spindle was fully submerged. Temperature was controlled by an external Brookfield TC-602P circulation bath, allowing viscosity data to be collected between 273.15 and $353.15 \mathrm{~K}$ as programmed. The cylinder and spindle were washed with acetone after the measurement of each sample was completed. The cylinder and spindle were then fully dried with air flow prior to starting the next run.

\subsection{Simulation Method}

Thermophysical properties of the studied set of $\mathrm{N}$-functionalized imidazole compounds were calculated using the COSMOtherm software package (BIOVIA COSMOtherm, Release 2020) [31], which had been shown to be a practical method of predicting the physical properties of imidazoles [20]. Due to the absence of the molecular structures of the selected $\mathrm{N}$-functionalized imidazole compounds in the COSMObase library provided by the software package, the necessary COSMO files were generated based on Density Functional Theory (DFT) calculations carried out with Gaussian 16, revision A.03 [32]. The optimized geometries of the structures were obtained using the BP86 functional $[33,34]$ and the TZVP basis set [35]. Single-point energy calculations were performed using the BP86 functional and TZVP basis set with the COSMO-RS solvation model [36,37] to obtain the necessary COSMO files. This work followed the procedure of previous studies that utilized COSMOtherm to predict the properties of imidazole-based ILs [20,38-40]. Finally, we performed COSMO calculations in COSMOtherm (BIOVIA COSMOtherm, Release 2020) at the TZVP level.

Densities $(\rho)$ and dynamic viscosities $(\eta)$ were calculated for each of the $\mathrm{N}$-functionalized imidazole compounds over a temperature range of 293.15-353.15 K. Enthalpy of vaporization $(\Delta H)$ and vapor pressures $(P)$ were also calculated for each of the $\mathrm{N}$-functionalized imidazole compounds over a temperature range of 283.4-323.0 K for N-isopropylimidazole, 289.6-326.1 K for N-isobutylimidazole, 295.7-330.2 K for N-sec-butylimidazole, 303.0-343.3 K for N-cyclopropylmethylimidazole, 305.0-346.1 K for N-cyclopentylimidazole, and 314.0-352.8 K for $\mathrm{N}$-cyclohexylmethylimidazole. Based on a comparison of the experimental and simulated 
viscosities, we defined a correction factor of 1.3 to the viscosities calculated by COSMOtherm as follows:

$$
\eta_{c}^{c}=1.3 * \eta_{c}
$$

where $\eta_{c}^{c}$ is the corrected viscosity (in $\mathrm{mPa} \cdot \mathrm{s}$ ), and $\eta_{c}$ is the viscosity (in $\mathrm{mPa} \cdot \mathrm{s}$ ) calculated in COSMOtherm.

\section{Results and Discussion}

\subsection{Densities of Branched and Cycloalkyl Imidazole Compounds}

Density values of branched and cycloalkyl imidazole compounds from measurement and COSMOtherm calculation results over the temperature range of $293.15-353.15 \mathrm{~K}$, along with the error between computation and measurement, are shown in Table 2. Density data for $\mathrm{N}$-cyclohexylmethylimidazole were not collected as this compound is solid at room temperature and could not be injected into the densitometer.

Table 2. Densities $(\rho)$ of imidazole compounds from measurements and COSMOtherm calculations at different temperatures $(T)$ and $P=101 \mathrm{kPa}^{\mathrm{a}}$.

\begin{tabular}{|c|c|c|c|c|c|c|c|}
\hline$\frac{T}{\mathrm{~K}}$ & $\frac{\rho_{m} \mathrm{~b}}{\mathrm{~g} \cdot \mathrm{cm}^{-3}}$ & $\frac{\rho_{c}^{c}}{\mathrm{~g} \cdot \mathrm{cm}^{-3}}$ & $\frac{\text { Error }^{\mathrm{d}}}{\%}$ & $\begin{array}{l}T \\
\mathrm{~K}\end{array}$ & $\frac{\rho_{m}}{\mathrm{~g} \cdot \mathrm{cm}^{-3}}$ & $\frac{\rho_{c}}{\mathrm{~g} \cdot \mathrm{cm}^{-3}}$ & $\frac{\text { Error }}{\%}$ \\
\hline \multicolumn{4}{|c|}{ (1) N-isopropylimidazole } & \multicolumn{4}{|c|}{ (2) N-isobutylimidazole } \\
\hline 293.15 & 0.96927 & 0.96079 & 0.88 & 293.15 & 0.94471 & 0.93562 & 0.96 \\
\hline 303.15 & 0.96079 & 0.95101 & 1.02 & 303.15 & 0.93675 & 0.92597 & 1.15 \\
\hline 313.15 & 0.95231 & 0.94132 & 1.15 & 313.15 & 0.92879 & 0.91643 & 1.33 \\
\hline 323.15 & 0.94379 & 0.93172 & 1.28 & 323.15 & 0.92081 & 0.90698 & 1.50 \\
\hline 333.15 & 0.93525 & 0.92222 & 1.39 & 333.15 & 0.91280 & 0.89763 & 1.66 \\
\hline 343.15 & 0.92667 & 0.91280 & 1.50 & 343.15 & 0.90476 & 0.88838 & 1.81 \\
\hline 353.15 & 0.91804 & 0.90348 & 1.59 & 353.15 & 0.89678 & 0.87923 & 1.96 \\
\hline \multicolumn{4}{|c|}{ (3) N-sec-butylimidazole } & \multicolumn{4}{|c|}{ (4) N-cyclopropylmethylimidazole } \\
\hline 293.15 & 0.95106 & 0.93546 & 1.64 & 293.15 & 1.02976 & 1.03326 & -0.34 \\
\hline 303.15 & 0.94302 & 0.92579 & 1.83 & 303.15 & 1.02154 & 1.02327 & -0.17 \\
\hline 313.15 & 0.93502 & 0.91623 & 2.01 & 313.15 & 1.01335 & 1.01332 & 0.00 \\
\hline 323.15 & 0.92698 & 0.90676 & 2.18 & 323.15 & 1.00513 & 1.00344 & 0.17 \\
\hline 333.15 & 0.91895 & 0.89740 & 2.35 & 333.15 & 0.99690 & 0.99361 & 0.33 \\
\hline 343.15 & 0.91091 & 0.88813 & 2.50 & 343.15 & 0.98866 & 0.98385 & 0.49 \\
\hline 353.15 & 0.90280 & 0.87897 & 2.64 & 353.15 & 0.98035 & 0.97415 & 0.63 \\
\hline \multicolumn{8}{|c|}{ (5) N-cyclopentylimidazole } \\
\hline 293.15 & 1.04677 & 1.05621 & -0.90 & & & & \\
\hline 303.15 & 1.03893 & 1.04605 & -0.68 & & & & \\
\hline 313.15 & 1.03091 & 1.03594 & -0.49 & & & & \\
\hline 323.15 & 1.02286 & 1.02588 & -0.30 & & & & \\
\hline 333.15 & 1.01481 & 1.01588 & -0.10 & & & & \\
\hline 343.15 & 1.00677 & 1.00593 & 0.08 & & & & \\
\hline 353.15 & 0.99869 & 0.99604 & 0.26 & & & & \\
\hline
\end{tabular}

${ }^{\text {a }}$ Uncertainties are $u(T)=0.01 \mathrm{~K}$ and $u(\rho)=0.00001 \mathrm{~g} \cdot \mathrm{cm}^{-3} ;{ }^{\mathrm{b}}$ Measured density; ${ }^{\mathrm{c}}$ COSMOtherm calculated density; ${ }^{\mathrm{d}}$ Error $=\frac{\rho_{m}-\rho_{c}}{\rho_{m}} \times 100$.

As expected, density decreases with increasing temperature, which inversely correlates to volume expansion caused by increased molecular motion. For branched imidazole compounds 1, 2 and 3, the isopropyl group is denser than the iso/sec butyl group. To explain this phenomenon, the addition of carbon from the isopropyl to iso/sec-butyl group is regarded as a volume dilution of the imidazole ring which exhibits high density. However, this trend does not apply to cycloalkyl imidazole compounds in that density increases from compound 4 to compound 5 as one more carbon is incorporated to the alkyl group moiety. It is also noted that cyclization contributes to density increment as compound $\mathbf{4}$ is denser than compounds 2 and 3, although they share the same number of carbon atoms. To illustrate the effect of branching and cyclization on compound density, data for corresponding linear alkyl imidazoles published in our previous work [22] are compiled in Table S1. When comparing alkyl compounds with the same number of carbon atoms, density of imidazole 
compounds follows the order of branched $<$ linear $<$ cycloalkyl. The decrease in density from linear to branched imidazole might be attributed to the decreased packing efficiency, in which alkyl chain is reorganized and occupies more volume. This phenomenon agrees well with the trend of density change in isomers with different configurations (i.e., butanol vs. isobutanol/sec-butanol) and even in polymers (i.e., HDPE vs. LDPE). However, the density increments from linear to cycloalkyl imidazole indicate a reduction of molar volume, which is opposite to the branching effect when carbocyles are regarded as a special form of branching, where branches share both starting and end point. Thus, the effects of carbocyclic substituents should be considered. Here the increase in density of cycloalkyl imidazole can be explained as the result of reduction in degree of freedom brought by cyclization, causing the reduction of possible conformations associated with enhanced approachability between molecules and reduced intermolecular space.

Apart from experimental density data, results from COSMOtherm calculations in Table 2 showed the same trend associated with changes in molecule configuration and temperature and are close to measured values with maximum absolute percentage error as $2.64 \%$, indicating the suitability of using COSMOtherm for density simulation.

Measured density data of imidazole compounds are presented in Figure 1, from which a clear sequence in order of magnitude can be determined. Moreover, a linear fit model was first applied to each compound for its simplicity, and corresponding fit parameters are shown in Table 3. The accuracy of linear regression evaluation is reflected by coefficient of determination $\left(R^{2}\right)$ value of 1.0000 for all the five compounds. However, the maximum absolute residuals varying between $0.4 \times 10^{-4}$ and $1.2 \times 10^{-4}$ along with the residual sum of squares (RSS) values between $0.486 \times 10^{-8}$ and $2.825 \times 10^{-8}$ show evident residual deviations. To narrow down the prediction error, a parabolic model in the form of

$$
\rho=A+B \cdot\left(T-T_{0}\right)+C \cdot\left(T-T_{0}\right)^{2}
$$

was then utilized and corresponding parameters are shown in Table 4. In comparison with the linear model, the maximum absolute residual of the parabolic model decreases by $25-87.5 \%$ and the RSS decreases by $65.2-99.5 \%$ for compound $1-5$, indicating improved restriction on residual deviations. As a result, the parabolic equations derived are more suitable than the linear ones for predictions of compound density ranging from 293.15 to $353.15 \mathrm{~K}$.

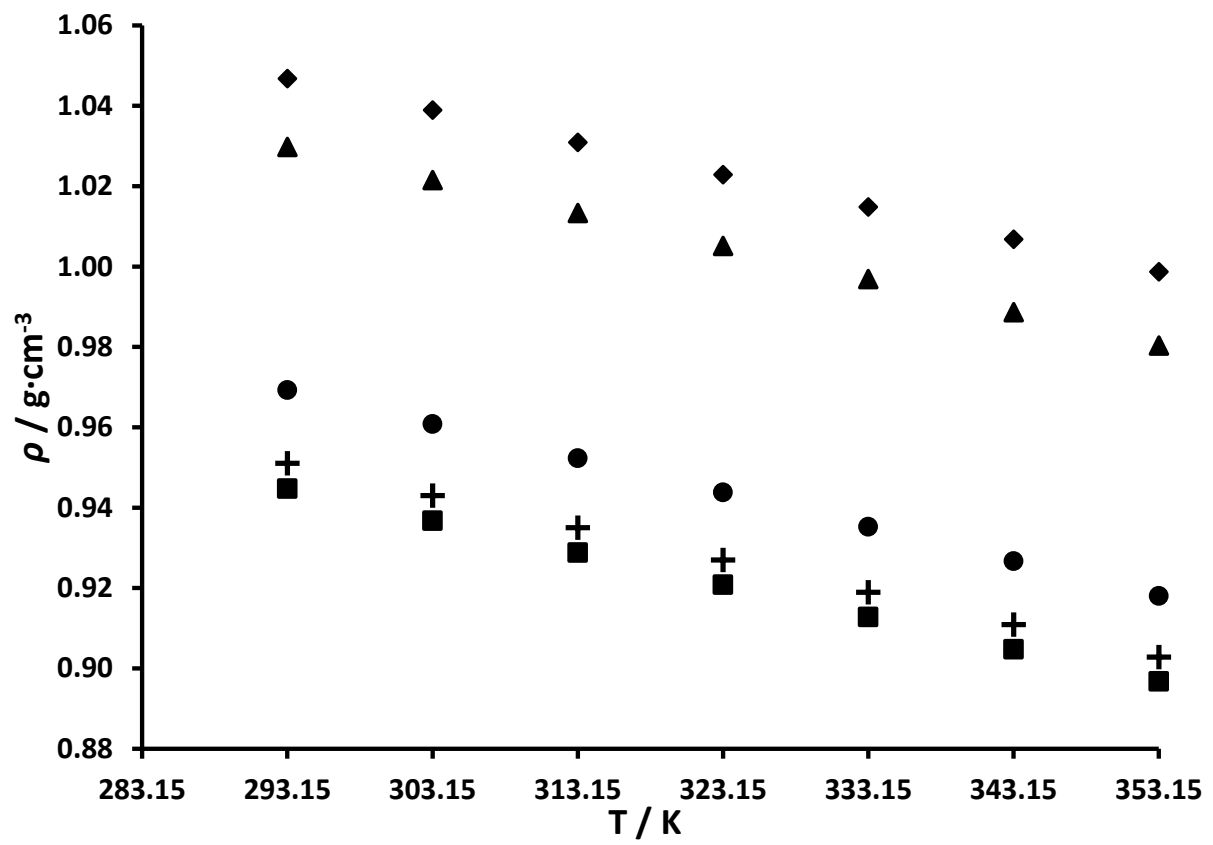

Figure 1. Temperature dependence of density of imidazole compounds. Circle = compound (1); square $=$ compound (2); cross $=$ compound (3); triangle $=$ compound (4); diamond = compound (5) . 
Table 3. Parameters of linear density-temperature equation $(\rho=-a \cdot T+b)$ derived from measurement data for imidazole compounds within temperature range of 293.15-353.15 K.

\begin{tabular}{cccccc}
\hline Compound & $\frac{a}{\mathbf{g} \cdot \mathbf{c m}^{-3} \cdot \mathbf{K}^{-1}}$ & $\frac{\boldsymbol{b}}{\mathbf{g} \cdot \mathbf{c m}^{-3}}$ & $\mathbf{R}^{2}$ & Maximum Absolute Residual & RSS \\
\hline 1 & $8.5354 \times 10^{-4}$ & 1.220 & 1.0000 & $0.8 \times 10^{-4}$ & $2.030 \times 10^{-8}$ \\
2 & $7.9914 \times 10^{-4}$ & 1.179 & 1.0000 & $0.4 \times 10^{-4}$ & $0.503 \times 10^{-8}$ \\
3 & $8.0382 \times 10^{-4}$ & 1.187 & 1.0000 & $0.5 \times 10^{-4}$ & $0.486 \times 10^{-8}$ \\
4 & $8.2300 \times 10^{-4}$ & 1.271 & 1.0000 & $0.6 \times 10^{-4}$ & $0.749 \times 10^{-8}$ \\
5 & $8.0236 \times 10^{-4}$ & 1.282 & 1.0000 & $1.2 \times 10^{-4}$ & $2.825 \times 10^{-8}$ \\
\hline
\end{tabular}

Table 4. Parameters of parabolic density-temperature equation $\left(\rho=A+B \cdot\left(T-T_{0}\right)+C \cdot\left(T-T_{0}\right)^{2}\right)$ derived from measurement data for imidazole compounds studied in this work within temperature range of $293.15-353.15 \mathrm{~K}$.

\begin{tabular}{ccccccc}
\hline Compound & $\frac{A}{\mathbf{g} \cdot \mathrm{cm}^{-3}}$ & $\frac{B}{\mathbf{g} \cdot \mathbf{c m}^{-3} \cdot \mathbf{K}^{-\mathbf{1}}}$ & $\frac{C}{\mathbf{g} \cdot \mathbf{c m}^{-3} \cdot \mathbf{K}^{-2}}$ & $\frac{T_{0}}{\mathbf{K}}$ & Maximum Absolute Residual & RSS \\
\hline 1 & 0.9438 & $-0.8535 \times 10^{-3}$ & $-1.502 \times 10^{-7}$ & 323.15 & $0.1 \times 10^{-4}$ & $0.011 \times 10^{-8}$ \\
2 & 0.8968 & $-0.8027 \times 10^{-3}$ & $-0.610 \times 10^{-7}$ & 353.15 & $0.3 \times 10^{-4}$ & $0.133 \times 10^{-8}$ \\
3 & 0.9670 & $-0.7964 \times 10^{-3}$ & $-0.730 \times 10^{-7}$ & 273.15 & $0.3 \times 10^{-4}$ & $0.169 \times 10^{-8}$ \\
4 & 1.0379 & $-0.8145 \times 10^{-3}$ & $-1.053 \times 10^{-7}$ & 283.15 & $0.3 \times 10^{-4}$ & $0.165 \times 10^{-8}$ \\
5 & 0.9987 & $-0.8116 \times 10^{-3}$ & $-1.554 \times 10^{-7}$ & 353.15 & $0.6 \times 10^{-4}$ & $0.813 \times 10^{-8}$ \\
\hline
\end{tabular}

\subsection{Viscosity of Branched and Cycloalkyl Imidazole Compounds}

While COSMOtherm shows good reliability in predictions on compound density, the agreement of viscosity calculations with experiments are not as close. As a result, a correction factor of 1.3 was used to better approximate experimental data from computational estimates. Viscosity values of branched and cycloalkyl imodazole compounds from measurements and corrected COSMOtherm calculations over the temperature range of 293.15-353.15 K, along with the percentage errors, are shown in Table 5 with an exception of N-cyclohexylmethylimidazole starting from $323.15 \mathrm{~K}$ to $353.15 \mathrm{~K}$ as it melts when it's heated over $318.15 \mathrm{~K}$. Unscaled data from the COSMOtherm calculations are provided in Table S2.

Table 5. Viscosities $(\eta)$ of imidazole compounds from measurements and corrected COSMOtherm calculations at different temperatures $(T)$ and $P=101 \mathrm{kPa}$.

\begin{tabular}{|c|c|c|c|c|c|c|c|}
\hline$\frac{T}{\mathrm{~K}}$ & $\frac{\eta_{m} \mathrm{~b}}{\mathrm{mPa} \cdot \mathrm{s}}$ & $\frac{\eta_{c}^{c \mathrm{c}}}{\mathrm{mPa} \cdot \mathrm{s}}$ & $\frac{\text { Error }^{\mathrm{d}}}{\%}$ & $\frac{T}{\mathrm{~K}}$ & $\frac{\eta_{m}}{\mathrm{mPa} \cdot \mathrm{s}}$ & $\frac{\eta_{c}^{c}}{\mathrm{mPa} \cdot \mathbf{s}}$ & $\frac{\text { Error }}{\%}$ \\
\hline \multicolumn{4}{|c|}{ (1) N-isopropylimidazole } & \multicolumn{4}{|c|}{ (2) N-isobutylimidazole } \\
\hline 293.15 & 3.11 & 3.10 & 0.45 & 293.15 & 4.76 & 3.70 & 22.28 \\
\hline 298.15 & 2.74 & 2.79 & -1.71 & 298.15 & 4.08 & 3.31 & 18.84 \\
\hline 303.15 & 2.46 & 2.52 & -2.33 & 303.15 & 3.54 & 2.97 & 15.97 \\
\hline 308.15 & 2.20 & 2.28 & -3.70 & 308.15 & 3.10 & 2.68 & 13.50 \\
\hline 313.15 & 1.99 & 2.07 & -4.22 & 313.15 & 2.75 & 2.43 & 11.80 \\
\hline 318.15 & 1.80 & 1.89 & -5.07 & 318.15 & 2.45 & 2.20 & 10.18 \\
\hline 323.15 & 1.64 & 1.73 & -5.45 & 323.15 & 2.18 & 2.00 & 8.13 \\
\hline 333.15 & 1.35 & 1.46 & -7.99 & 333.15 & 1.78 & 1.67 & 6.02 \\
\hline 343.15 & 1.10 & 1.24 & -12.84 & 343.15 & 1.50 & 1.41 & 5.87 \\
\hline 353.15 & 0.93 & 1.07 & -14.68 & 353.15 & 1.21 & 1.20 & 0.56 \\
\hline \multicolumn{4}{|c|}{ (3) N-sec-butylimidazole } & \multicolumn{4}{|c|}{ (4) N-cyclopropylmethylimidazole } \\
\hline 293.15 & 4.22 & 3.65 & 13.48 & 293.15 & 7.06 & 4.92 & 30.32 \\
\hline 298.15 & 3.62 & 3.27 & 9.69 & 298.15 & 6.00 & 4.36 & 27.28 \\
\hline 303.15 & 3.15 & 2.94 & 6.73 & 303.15 & 5.14 & 3.89 & 24.41 \\
\hline 308.15 & 2.75 & 2.65 & 3.65 & 308.15 & 4.48 & 3.47 & 22.48 \\
\hline 313.15 & 2.45 & 2.40 & 2.15 & 313.15 & 3.94 & 3.12 & 20.92 \\
\hline
\end{tabular}


Table 5. Cont.

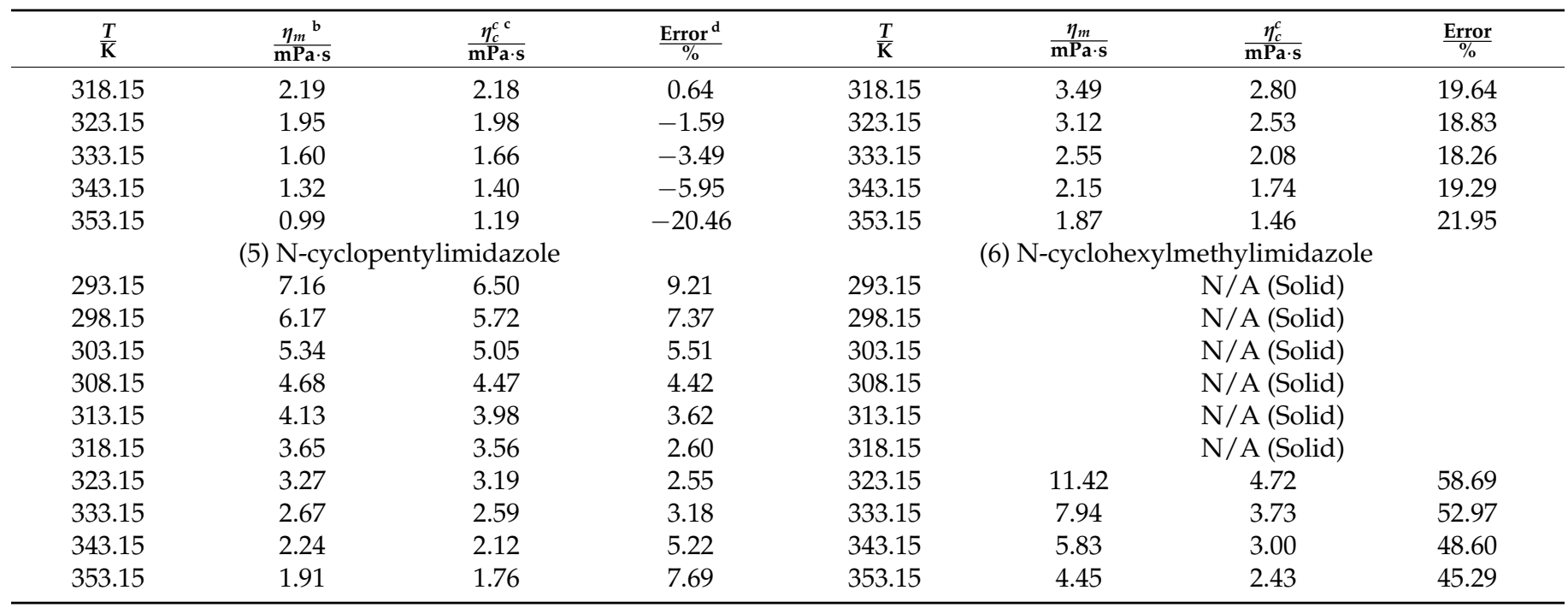

a Temperature variance is $\pm 0.01 \mathrm{~K}$. Viscosity measurements variance is $\pm 0.1 \%$ of the reported value; ${ }^{\mathrm{b}}$ Measured viscosity; ${ }^{\mathrm{C}}$ Corrected COSMOtherm viscosity, corrected viscosity $\left(\eta_{c}^{c}\right)=1.3 \times$ calculated viscosity by COSMOtherm $\left(\eta_{c}\right) ;{ }^{\mathrm{d}}$ Error $=\frac{\eta_{m}-\eta_{c}^{c}}{\eta_{c}^{c}} \times 100$.

As shown in Table 4, almost all measured viscosities were $<10 \mathrm{cP}$ with the only exception of compound 6 at $323.15 \mathrm{~K}$, the first viscosity data point obtained above the compound's melting point. Similar to the trend of change in density, viscosity for each compound decreases when heated due to enhanced molecular diffusion. For all six compounds shown in Table 5, viscosities of either branched or cyclized imidazoles increase upon addition of carbon atoms and this phenomenon has also been observed for linear alkyl imidazole analogues [22]. However, when comparing viscosity of linear (Table S3) and branched imidazoles, there was not a certain trend of behavior as found in density analysis. Viscosity of compound $\mathbf{1}$ is lower than its linear isomer, N-propylimidazole, across the temperature range of measurement, while compound $\mathbf{2}$ and compound $\mathbf{3}$ are of higher viscosity at low temperature and become less viscous than N-butylimidazole when heated over $343.15 \mathrm{~K}$ and $318.15 \mathrm{~K}$, respectively. Unlike branched imidazole compounds exhibiting viscosities close to corresponding linear analogues, notable increases in viscosity are observed for the transformation from linear to cycloalkyl imidazoles. For instance, at $323.15 \mathrm{~K}$, viscosity increases by $56.8 \%$ from N-butylimidazole to compound $4,35.1 \%$ from $\mathrm{N}$-pentylimidazole to compound $\mathbf{5}$ and $\mathbf{2 0 3 . 7 \%}$ from $\mathrm{N}$-octylimidazole to compound $\mathbf{6}$. As indicated by density, $\mathrm{N}$-cycloalkylimidazole molecules share less intermolecular volume than linear alkylimidazoles, which means they are packed more closely, and thus increased van der Waals interactions result in the increment in viscosity of cycloalkylimidazoles. Apart from comparisons on viscosity values, it is found that viscosity of linear alkyl imidazoles change less with temperature. For example, viscosity of N-butylimidazole decreases by $64.1 \%$ from 293.15 to $353.15 \mathrm{~K}$, while the reductions for compounds 2,3 , and 4 are $74.6 \%$, 76.5 and $73.5 \%$, respectively.

To better understand the tendency of compound viscosity with respect to temperature, experimental data are plotted in Figure 2. Unlike density, viscosity followed a non-linear trend. Among several empirical equations that can be used to model viscosity-temperature relationship, the Andrade Equation [41], in the form of $\eta=a \cdot \exp \cdot\left(b \cdot T^{-1}\right)$, was chosen first, for its simplicity and effectiveness in our prior work [42-44]. Parameters for the Andrade equation are presented in Table 6, coefficients of determination $\left(R^{2}\right)$ for all equations derived for branched and cycloalkyl imidazoles considered in this work are $>0.99$ while the broad residual deviations indicated by the maximium absolute residual and SSR values call for model improvement. Consequently, the Vogel-Fulcher-Tammann equation [45] in the form of

$$
\eta=A \cdot \exp \cdot\left(B \cdot\left(T-T_{0}\right)^{-1}\right.
$$


was used correlating viscosity and temperature. Fit parameters can be found in Table 7. For each imidazole compound, the maximium absolute residual value is smaller than corresponding data in Table 6 for the Andrade Equation. Moreover, the SSR value reduced by at least 3 orders of magnitude also indicates the superiority of the Vogel-FulcherTammann equation over Andrade Equation for predictions of compound viscosity in the range of $293.15-353.15 \mathrm{~K}$.

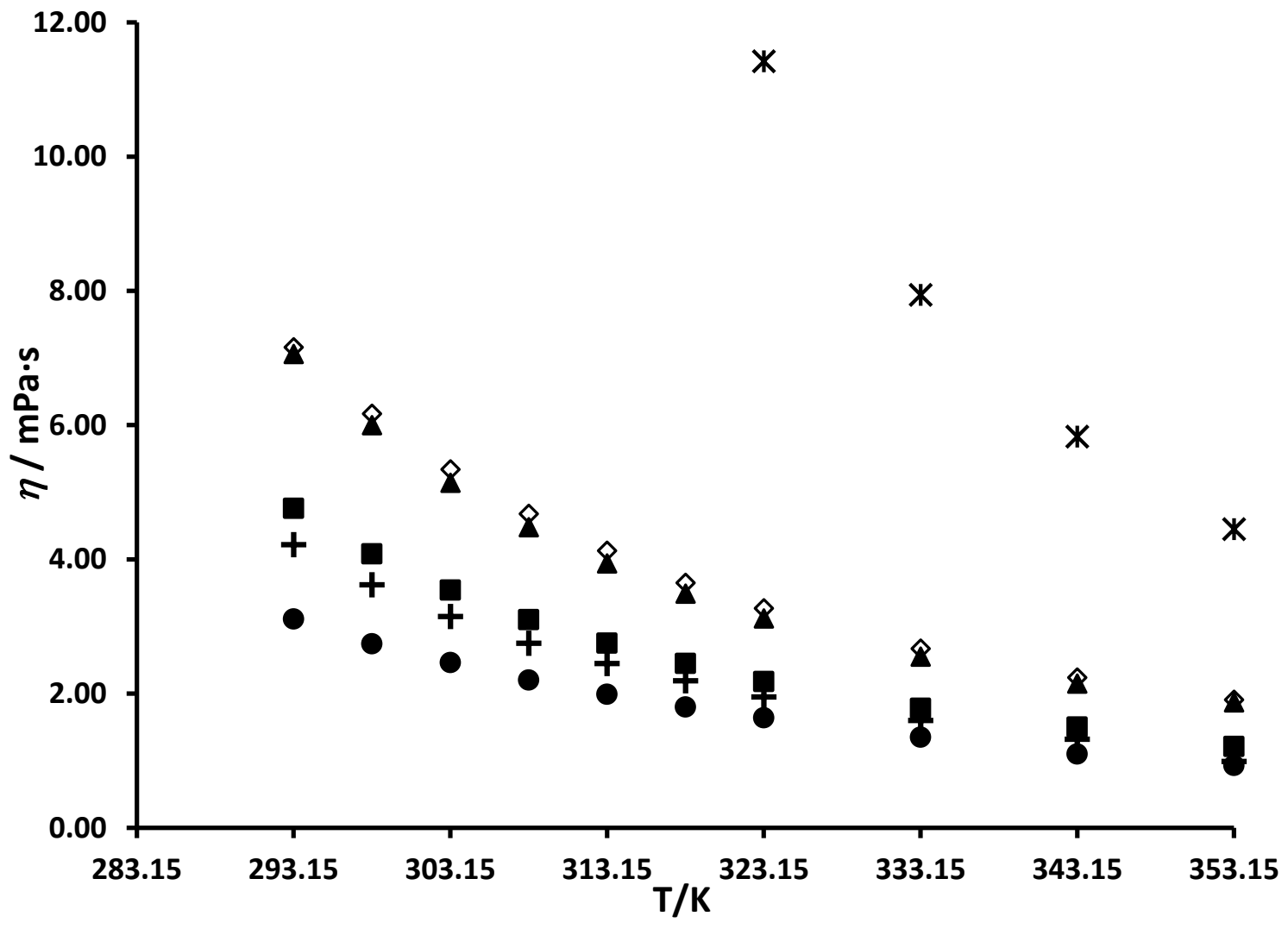

Figure 2. Temperature dependence of viscosity of imidazole compounds. Circle = compound (1); square $=$ compound (2); cross = compound (3); triangle = compound (4); unfilled diamond = compound (5); snowflake $=$ compound $(6)$.

Table 6. Andrade equation $\left(\eta=a \cdot \exp \cdot\left(b \cdot T^{-1}\right)\right)$ parameters derived from measurement data for imidazole compounds.

\begin{tabular}{cccccc}
\hline Compound & $\frac{a}{\mathbf{m P a} \cdot \mathbf{s}}$ & $\frac{b}{\mathbf{K}}$ & $\mathbf{R}^{\mathbf{2}}$ & Maximum Absolute Residual & RSS \\
\hline 1 & $0.2670 \times 10^{-2}$ & $2.070 \times 10^{3}$ & 0.9994 & 0.03 & 0.0020 \\
2 & $0.1687 \times 10^{-2}$ & $2.320 \times 10^{3}$ & 0.9985 & 0.14 & 0.0277 \\
3 & $0.1161 \times 10^{-2}$ & $2.399 \times 10^{3}$ & 0.9972 & 0.37 & 0.0136 \\
4 & $0.2619 \times 10^{-2}$ & $2.230 \times 10^{3}$ & 0.9937 & 0.24 & 0.2178 \\
5 & $0.2838 \times 10^{-2}$ & $2.286 \times 10^{3}$ & 0.9971 & 0.16 & 0.1010 \\
6 & $0.0172 \times 10^{-2}$ & $3.584 \times 10^{3}$ & 0.9984 & & 0.0517 \\
\hline
\end{tabular}

\subsection{Simulations on Vapor Pressure and Vaporization Enthalpy}

Vapor pressures of branched and cycloalkyl imidazoles considered have been measured previously and enthalpies of vaporization were calculated accordingly [30]. COSMOtherm calculations were applied in the current study with the complete results shown in Table 44 with compilation of measured values for comparison purpose. Data obtained at relatively low temperature (283-326 K) in the whole temperature range of consideration $(280-350 \mathrm{~K})$ were selected and presented in Table 8. It is noted that that COSMOtherm results on vapor pressure are close to measured values at lower temperature $(<300 \mathrm{~K})$ for 
branched imidazoles while variances in percentage error are much more scattered between cycloalkyl imidazoles. Moreover, as can be seen in Table S4, the error associated with vapor pressure predictions for all compounds tended to expand along with increased temperature. Unlike vapor pressure, variances in the simulation results for vaporization enthalpies were relatively consistent and acceptable, with absolute percentage error ranging from $0.84-12.31 \%$ for all compounds considered. Among these, compound 4 exhibited the best accuracy on vaporization enthalpy prediction (percentage error: $0.84-3.42 \%$ ), despite a considerable gap found in vapor pressure estimations.

Table 7. Vogel-Fulcher-Tammann equation $\left(\eta=A \cdot \exp \cdot\left(B \cdot\left(T-T_{0}\right)^{-1}\right)\right)$ parameters derived from measurement data for imidazole compounds.

\begin{tabular}{ccccc}
\hline Compound & $\frac{A}{\mathrm{mPa} \cdot \mathbf{s}}$ & $\frac{B}{\mathrm{~K}}$ & $\frac{T_{0}}{\mathrm{~K}}$ & Maximum Absolute Residual \\
\hline 1 & $0.0438 \times 10^{-1}$ & $1.786 \times 10^{3}$ & 21.01 & 0.02 \\
2 & $0.3290 \times 10^{-1}$ & $0.806 \times 10^{3}$ & 131.06 & 0.03 \\
3 & $0.0470 \times 10^{-1}$ & $1.590 \times 10^{3}$ & 59.11 & 0.06 \\
4 & $1.7126 \times 10^{-1}$ & $0.397 \times 10^{3}$ & 186.34 & 0.02 \\
5 & $0.8963 \times 10^{-1}$ & $0.605 \times 10^{3}$ & 155.13 & 0.02 \\
6 & $0.8476 \times 10^{-1}$ & $0.617 \times 10^{3}$ & 197.37 & $0.018 \times 10^{-5}$ \\
\hline
\end{tabular}

Table 8. Selected vapor pressure $(P)$ and enthalpies of vaporization $(\Delta H)$ of imidazole compounds from measurements and COSMOtherm calculations at different temperatures $(T)^{\text {a }}$.

\begin{tabular}{|c|c|c|c|c|c|c|c|}
\hline Compound & $\frac{T}{\mathrm{~K}}$ & $\frac{P_{m} \mathrm{~b}}{\mathrm{~Pa}}$ & $\frac{P_{c}{ }^{c}}{P a}$ & $\frac{\operatorname{Error}(P)^{\mathrm{d}}}{\%}$ & $\frac{\Delta H_{\text {vap }}^{m} \mathrm{e}^{\mathrm{k}}}{\mathrm{kJ} \cdot \mathrm{mol}^{-1}}$ & $\frac{\Delta H_{\text {vap }}^{c}{ }^{\mathrm{f}}}{\mathrm{kJ} \cdot \mathrm{mol}^{-1}}$ & $\frac{\operatorname{Error}\left(\Delta H_{\text {vap }}\right)^{\mathrm{g}}}{\%}$ \\
\hline \multirow{2}{*}{1} & 283.4 & 5.04 & 5.23 & -3.74 & 59.39 & 54.61 & 8.04 \\
\hline & 289.4 & 8.51 & 8.45 & 0.74 & 58.98 & 54.43 & 7.72 \\
\hline \multirow[b]{2}{*}{2} & 289.6 & 4.42 & 4.37 & 1.07 & 62.81 & 56.97 & 9.30 \\
\hline & 292.6 & 5.85 & 5.57 & 4.75 & 62.57 & 56.88 & 9.10 \\
\hline \multirow{2}{*}{3} & 295.7 & 7.11 & 6.84 & 3.78 & 64.78 & 56.81 & 12.31 \\
\hline & 298.4 & 8.99 & 8.43 & 6.22 & 64.57 & 56.72 & 12.61 \\
\hline \multirow{2}{*}{4} & 303.0 & 3.70 & 7.25 & -95.88 & 59.49 & 57.46 & 3.42 \\
\hline & 305.4 & 4.54 & 8.67 & -90.95 & 59.32 & 57.38 & 3.27 \\
\hline \multirow{2}{*}{5} & 305.0 & 2.42 & 2.16 & 10.79 & 70.1 & 61.53 & 12.23 \\
\hline & 308.0 & 3.19 & 2.73 & 14.29 & 69.87 & 61.43 & 12.08 \\
\hline \multirow{2}{*}{6} & 323.1 & 2.55 & 1.77 & 30.69 & 75.41 & 67.15 & 10.96 \\
\hline & 326.0 & 3.24 & 2.21 & 31.88 & 75.16 & 67.04 & 10.80 \\
\hline
\end{tabular}

${ }^{\text {a }}$ Uncertainties are $u(T)=0.1 \mathrm{~K}$ and $u(P)=0.01 \mathrm{~Pa} ;{ }^{\mathrm{b}}$ Measured vapor pressure [30]; ${ }^{\mathrm{c}}$ COSMOtherm calculated vapor pressure; ${ }^{\mathrm{d}}$ Error $(P)=\frac{P_{m}-P_{c}}{P_{m}} * 100 ;{ }^{\mathrm{e}}$ Enthalpy of vaporization from measurement; ${ }^{\mathrm{f}}$ Enthalpy of vaporization from COSMOtherm calculation; ${ }^{\mathrm{g}} \operatorname{Error}\left(\Delta H_{\text {vap }}\right)=\frac{\Delta H_{\text {vap }}^{m}-\Delta H_{\text {vap }}^{m}}{\Delta H_{\text {vap }}^{n}} \times 100$.

\section{Conclusions}

In this work, two fundamental properties, density and viscosity, of selected branched and cycloalkyl imidazole compounds were characterized in temperature range of 293.15-353.15 K. Densities of alkyl imidazole compounds bearing the same number of carbon atoms are in the order of branched < linear < cycloalkyl. It was also found that the density of branched and linear alkyl imidazoles decrease upon addition of hydrocarbon moiety while cycloalkyl imidazoles showed an opposite tendency. No distinct variance in viscosity was observed for linear and branched imidazole, but cyclic groups were found to make imidazole compounds considerably more viscous. Densities and viscosities of imidazole compounds considered were in reasonable range. Data for density were fitted into a linear and parabolic model. Viscosity data were summarized using the Andrade Equation and the Vogel-FulcherTammann equation for understanding the temperature dependence of imidazole compounds on corresponding properties. Data obtained from experimental characterizations can be used for guidance of molecular design on branched and cycloalkyl imidazole analogues. Apart from property characterizations, COSMOtherm calculations applied for comparison showed 
excellent reliability for density simulations, while there might be more space for improvement in predictions of viscosity and vapor pressure.

Supplementary Materials: The following are available online at https:/ /www.mdpi.com/article/10 .3390 /liquids2010002/s1, Table S1: Compilation of densities $(\rho)$ of linear alkyl imidazoles at different temperatures $(T)$ and $P=101 \mathrm{kPa}$, Table S2: Dynamic viscosities $(\eta)$ of imidazole compounds from measurements and COSMOtherm calculations at different temperatures $(T)$ and $P=101 \mathrm{kPa}$, Table S3: Compilation of viscosities $(\eta)$ of linear alkyl imidazoles at different temperatures $(T)$ and $P=101 \mathrm{kPa}$, Table S4: Vapor pressure $(P)$ and enthalpies of vaporization $(\Delta H)$ of imidazole compounds from measurements and COSMOtherm calculations at different temperatures $(T)$.

Author Contributions: Conceptualization, S.Q. and J.E.B.; methodology, S.Q.; software, T.S.; validation, J.E.B. and T.S.; formal analysis, S.Q.; investigation, S.Q., P.M., A.C.I. and A.S.; resources, J.E.B. and T.S.; data curation, S.Q. and A.S.; writing-original draft preparation, S.Q.; writing-review and editing, J.E.B.; visualization, A.S. and T.S.; supervision, J.E.B. and T.S.; project administration, J.E.B. and T.S.; funding acquisition, J.E.B. All authors have read and agreed to the published version of the manuscript.

Funding: This research was funded by NSF, grant number 1851974 which provided support for P.M. to participate as an REU student.

Institutional Review Board Statement: Not applicable.

Informed Consent Statement: Not applicable.

Data Availability Statement: Data is contained within the article and supplementary material.

Acknowledgments: The authors thank the University of Alabama and the Office of Information Technology for providing high performance computing resources and support that have contributed to these research results. This work was made possible in part by a grant of high-performance computing resources and technical support from the Alabama Supercomputer Authority.

Conflicts of Interest: The authors declare no conflict of interest.

\section{References}

1. Ren, F.; Wang, J.; Xie, F.; Zan, K.; Wang, S.; Wang, S. Applications of ionic liquids in starch chemistry: A review. Green Chem. 2020, 22, 2162-2183. [CrossRef]

2. Krishnan, A.; Gopinath, K.P.; Vo, D.-V.N.; Malolan, R.; Nagarajan, V.M.; Arun, J. Ionic liquids, deep eutectic solvents and liquid polymers as green solvents in carbon capture technologies: A review. Environ. Chem. Lett. 2020, 18, 2031-2054. [CrossRef]

3. Bara, J.E.; Finotello, A.; Magee, J.W.; Qian, S.; O'Harra, K.E.; Dennis, G.P.; Noble, R.D. 110th Anniversary: Properties of Imidazolium-Based Ionic Liquids Bearing Both Benzylic and n-Alkyl Substituents. Ind. Eng. Chem. Res. 2019, 58, 17956-17964. [CrossRef]

4. Liu, X.; O'Harra, K.E.; Bara, J.E.; Turner, C.H. Molecular insight into the anion effect and free volume effect of $\mathrm{CO}_{2}$ solubility in multivalent ionic liquids. Phys. Chem. Chem. Phys. 2020, 22, 20618-20633. [CrossRef]

5. Atanassova, M. Solvent extraction chemistry in ionic liquids: An overview of f-ions. J. Mol. Liq. 2021, 343, 117530. [CrossRef]

6. Chatzimitakos, T.; Anagnostou, P.; Constantinou, I.; Dakidi, K.; Stalikas, C. Magnetic Ionic Liquids in Sample Preparation: Recent Advances and Future Trends. Separations 2021, 8, 153. [CrossRef]

7. Correia, D.M.; Fernandes, L.C.; Fernandes, M.M.; Hermenegildo, B.; Meira, R.M.; Ribeiro, C.; Ribeiro, S.; Reguera, J.; LancerosMéndez, S. Ionic Liquid-Based Materials for Biomedical Applications. Nanomaterials 2021, 11, 2401. [CrossRef]

8. Geniselli da Silva, V. Laccases and ionic liquids as an alternative method for lignin depolymerization: A review. Bioresour. Technol. Rep. 2021, 16, 100824. [CrossRef]

9. Shamsuri, A.A.; Abdan, K.; Kaneko, T. A Concise Review on the Physicochemical Properties of Biopolymer Blends Prepared in Ionic Liquids. Molecules 2021, 26, 216. [CrossRef]

10. Seng, L.K.; Masdar, M.S.; Shyuan, L.K. Ionic Liquid in Phosphoric Acid-Doped Polybenzimidazole (PA-PBI) as Electrolyte Membranes for PEM Fuel Cells: A Review. Membranes 2021, 11, 728. [CrossRef]

11. Ghandi, K. A Review of Ionic Liquids, Their Limits and Applications. Green Sustain. Chem. 2014, 4, 10. [CrossRef]

12. Yang, G.; Song, Y.; Wang, Q.; Zhang, L.; Deng, L. Review of ionic liquids containing, polymer/inorganic hybrid electrolytes for lithium metal batteries. Mater. Des. 2020, 190, 108563. [CrossRef]

13. Miao, L.; Song, Z.; Zhu, D.; Li, L.; Gan, L.; Liu, M. Ionic Liquids for Supercapacitive Energy Storage: A Mini-Review. Energy Fuels 2021, 35, 8443-8455. [CrossRef] 
14. Hindman, M.S.; Stanton, A.D.; Irvin, A.C.; Wallace, D.A.; Moon, J.D.; Reclusado, K.R.; Liu, H.; Belmore, K.A.; Liang, Q.; Shannon, M.S.; et al. Synthesis of 1,2-Dialkyl-, 1,4(5)-Dialkyl-, and 1,2,4(5)-Trialkylimidazoles via a One-Pot Method. Ind. Eng. Chem. Res. 2013, 52, 11880-11887. [CrossRef]

15. Ulewicz, M.; Radzyminska-Lenarcik, E. Application of Hydrophobic Alkylimidazoles in the Separation of Non-Ferrous Metal Ions across Plasticised Membranes-A Review. Membranes 2020, 10, 331. [CrossRef]

16. Radzyminska-Lenarcik, E.; Pyszka, I.; Urbaniak, W. Cadmium(II) and lead(II) extraction and transport through polymer inclusion membranes with 1-alkylimidazole. Desalin. Water Treat. 2021, 214, 56-63. [CrossRef]

17. Shannon, M.S.; Tedstone, J.M.; Danielsen, S.P.O.; Hindman, M.S.; Bara, J.E. Properties and Performance of Ether-Functionalized Imidazoles as Physical Solvents for $\mathrm{CO}_{2}$ Separations. Energy Fuels 2013, 27, 3349-3357. [CrossRef]

18. Barbosa, G.D.; Bara, J.E.; Weinman, S.T.; Turner, C.H. Molecular aspects of temperature swing solvent extraction for brine desalination using imidazole-based solvents. Chem. Eng. Sci. 2022, 247, 116866. [CrossRef]

19. Wang, J.; Li, C.; Shen, C.; Wang, Z. Towards understanding the effect of electrostatic interactions on the density of ionic liquids. Fluid Phase Equilibria 2009, 279, 87-91. [CrossRef]

20. Bara, J.E.; Moon, J.D.; Reclusado, K.R.; Whitley, J.W. COSMOTherm as a Tool for Estimating the Thermophysical Properties of Alkylimidazoles as Solvents for $\mathrm{CO}_{2}$ Separations. Ind. Eng. Chem. Res. 2013, 52, 5498-5506. [CrossRef]

21. Shannon, M.S.; Hindman, M.S.; Danielsen, S.P.O.; Tedstone, J.M.; Gilmore, R.D.; Bara, J.E. Properties of alkylbenzimidazoles for $\mathrm{CO}_{2}$ and $\mathrm{SO}_{2}$ capture and comparisons to ionic liquids. Sci. China Chem. 2012, 55, 1638-1647. [CrossRef]

22. Shannon, M.S.; Bara, J.E. Properties of Alkylimidazoles as Solvents for $\mathrm{CO}_{2}$ Capture and Comparisons to Imidazolium-Based Ionic Liquids. Ind. Eng. Chem. Res. 2011, 50, 8665-8677. [CrossRef]

23. Emel'yanenko, V.N.; Portnova, S.V.; Verevkin, S.P.; Skrzypczak, A.; Schubert, T. Building blocks for ionic liquids: Vapor pressures and vaporization enthalpies of 1-(n-alkyl)-imidazoles. J. Chem. Thermodyn. 2011, 43, 1500-1505. [CrossRef]

24. Garist, I.V.; Verevkin, S.P.; Bara, J.E.; Hindman, M.S.; Danielsen, S.P.O. Building Blocks for Ionic Liquids: Vapor Pressures and Vaporization Enthalpies of 1-(n-Alkyl)-benzimidazoles. J. Chem. Eng. Data 2012, 57, 1803-1809. [CrossRef]

25. Emel'yanenko, V.N.; Portnova, S.V.; Verevkin, S.P.; Skrzypczak, A. Building Blocks for Ionic Liquids: A Study of Alkyl Chain Length Dependence of Vaporization Enthalpies of 1-(n-Alkyl)-2-methylimidazoles. J. Chem. Eng. Data 2011, 56, 3532-3540. [CrossRef]

26. Verevkin, S.P.; Zaitsau, D.H.; Emel'yanenko, V.N.; Paulechka, Y.U.; Blokhin, A.V.; Bazyleva, A.B.; Kabo, G.J. Thermodynamics of Ionic Liquids Precursors: 1-Methylimidazole. J. Phys. Chem. B 2011, 115, 4404-4411. [CrossRef]

27. Turner, C.H.; Cooper, A.; Zhang, Z.; Shannon, M.S.; Bara, J.E. Molecular Simulation of the Thermophysical Properties of N-Functionalized Alkylimidazoles. J. Phys. Chem. B 2012, 116, 6529-6535. [CrossRef] [PubMed]

28. Lenarcik, B.; Ojczenasz, P. The influence of the size and position of the alkyl groups in alkylimidazole molecules on their acid-base properties. J. Heterocycl. Chem. 2002, 39, 287-290. [CrossRef]

29. Bara, J.E. Versatile and Scalable Method for Producing N-Functionalized Imidazoles. Ind. Eng. Chem. Res. 2011, 50, 13614-13619. [CrossRef]

30. Verevkin, S.P.; Zaitseva, K.V.; Stanton, A.D.; Hindman, M.S.; Irvin, A.C.; Bara, J.E. Building Blocks for Ionic Liquids: Vapor Pressures and Vaporization Enthalpies of N-Functionalized Imidazoles with Branched and Cycloalkyl Substituents. Ind. Eng. Chem. Res. 2015, 54, 9850-9856. [CrossRef]

31. BIOVIA COSMOtherm, Dassault Systèmes. Available online: https://www.3ds.com/products-services/biovia/products/ molecular-modeling-simulation/solvation-chemistry/biovia-cosmotherm/ (accessed on 30 January 2022).

32. Frisch, M.J.; Trucks, G.W.; Schlegel, H.B.; Scuseria, G.E.; Robb, M.A.; Cheeseman, J.R.; Scalmani, G.; Barone, V.; Petersson, G.A.; Nakatsuji, H.; et al. Gaussian 16 Rev. C.01; Gaussian, Inc.: Wallingford, CT, USA, 2016.

33. Perdew, J.P. Density-functional approximation for the correlation energy of the inhomogeneous electron gas. Phys. Rev. B 1986, 33, 8822-8824. [CrossRef] [PubMed]

34. Becke, A.D. Density-functional exchange-energy approximation with correct asymptotic behavior. Phys. Rev. A 1988, 38 , 3098-3100. [CrossRef] [PubMed]

35. Schäfer, A.; Huber, C.; Ahlrichs, R. Fully optimized contracted Gaussian basis sets of triple zeta valence quality for atoms Li to Kr. J. Chem. Phys. 1994, 100, 5829-5835. [CrossRef]

36. Eckert, F.; Klamt, A. Fast solvent screening via quantum chemistry: COSMO-RS approach. AIChE J. 2002, 48, 369-385. [CrossRef]

37. Klamt, A.; Eckert, F. COSMO-RS: A novel and efficient method for the a priori prediction of thermophysical data of liquids. Fluid Phase Equilibria 2000, 172, 43-72. [CrossRef]

38. Shannon, M.S.; Tedstone, J.M.; Danielsen, S.P.O.; Hindman, M.S.; Irvin, A.C.; Bara, J.E. Free Volume as the Basis of Gas Solubility and Selectivity in Imidazolium-Based Ionic Liquids. Ind. Eng. Chem. Res. 2012, 51, 5565-5576. [CrossRef]

39. Zhang, X.; Liu, Z.; Wang, W. Screening of ionic liquids to capture $\mathrm{CO}_{2}$ by COSMO-RS and experiments. AIChE J. 2008, 54, 2717-2728. [CrossRef]

40. Sumon, K.Z.; Henni, A. Ionic liquids for $\mathrm{CO}_{2}$ capture using COSMO-RS: Effect of structure, properties and molecular interactions on solubility and selectivity. Fluid Phase Equilibria 2011, 310, 39-55. [CrossRef]

41. Andrade, E.N.D.C. The Viscosity of Liquids. Nature 1930, 125, 309-310. [CrossRef]

42. Qian, S.; Liu, X.; Dennis, G.P.; Turner, C.H.; Bara, J.E. Properties of symmetric 1,3-diethers based on glycerol skeletons for $\mathrm{CO}_{2}$ absorption. Fluid Phase Equilibria 2020, 521, 112718. [CrossRef] 
43. Qian, S.; Liu, X.; Turner, C.H.; Bara, J.E. Synthesis and properties of symmetric glycerol-derived 1,2,3-triethers and 1,3-diether-2ketones for $\mathrm{CO}_{2}$ absorption. Chem. Eng. Sci. 2022, 248, 117150. [CrossRef]

44. Qian, S.; Liu, X.; Turner, C.H.; Bara, J.E. Glycerol-derived solvents containing two or three distinct functional groups enabled by trifluoroethyl glycidyl ether. AIChE J. 2022, e17533. [CrossRef]

45. Seeton, C.J. Viscosity-temperature correlation for liquids. Tribol. Lett. 2006, 22, 67-78. [CrossRef] 